\title{
Bilateral Chronic Subdural Hematoma in the Posterior Fossa Treated with a Burr Hole Irrigation: A Case Report and Review of the Literature
}

\author{
Takuro Inoue Hisao Hirai Ayako Shima Fumio Suzuki \\ Masayuki Matsuda \\ Department of Neurosurgery, Koto Memorial Hospital, Shiga, Japan
}

\section{Keywords}

Case report $\cdot$ Chronic subdural hematoma Posterior fossa

\begin{abstract}
Chronic subdural hematoma (CSH) in the posterior fossa is extremely rare. The surgical strategy is still controversial. We report a case of bilateral CSH in the posterior fossa successfully treated with a single-burr hole surgery. A 74-year-old man under anticoagulation and antiplatelet therapy developed headache and nausea during observation for an asymptomatic supratentorial CSH. Radiological examinations revealed appearance of bilateral CSH in the posterior fossa associated with hydrocephalus. Upon rapid deterioration of the patient's consciousness, an urgent treatment was required. A burr hole was made near the transverse-sigmoid junction on the left side to access the hematoma. No ventricular drainage was placed as his consciousness improved during the decompression of the hematoma. Postoperative computed tomography showed that bilateral CSH and hydrocephalus had been successfully treated. In bilateral
\end{abstract}




\section{Case Reports in Neurology}

Case Rep Neurol 2019;11:87-93

DOI: $10.1159 / 000498856$

(C) 2019 The Author(s). Published by S. Karger AG, Basel www.karger.com/crn

Inoue et al.: Bilateral Chronic Subdural Hematoma in the Posterior Fossa Treated with a Burr Hole Irrigation: A Case Report and Review of the Literature

$\mathrm{CSH}$ in the posterior fossa, there may be a connection between each side. CSH in the posterior fossa, when urgent, can be treated under local anesthesia with a unilateral burr hole irrigation.

(C) 2019 The Author(s)

Published by S. Karger AG, Basel

\section{Introduction}

Chronic subdural hematoma (CSH) in the posterior fossa is extremely rare [1-13]. Different from supratentorial $\mathrm{CSH}$, the optimal treatment has not been elucidated yet. Space-occupying lesions in the posterior fossa, associated with hydrocephalus, need an urgent treatment. However, the optimal surgical treatment is a matter of debate due to its scarcity. We report a case of bilateral CSH in the posterior fossa associated with hydrocephalus, which was successfully treated with a burr hole irrigation from one side under local anesthesia.

\section{Case Report}

A 74-year-old man under anticoagulation and antiplatelet therapy after mitral valve replacement surgery had mild head injury in May 2017. Computed tomography (CT) taken 2 months later revealed the presence of supratentorial CSH on the left. He had been observed without surgical exploration because he had no neurological symptom and there was prolonged coagulation due to the anticoagulation and antiplatelet therapy. The patient was followed up regularly, and the CSH did not show any change in size. In July 2018, he presented with aggravating headache and nausea which lasted for 3 days. He showed slight consciousness disturbance (Glasgow Coma Scale: 14) at the time of admission, which deteriorated within a few hours thereafter. No other neurological signs and symptoms were present. A CT scan taken on his admission demonstrated an appearance of bilateral CSH in the posterior fossa associated with hydrocephalus (Fig. 1). Magnetic resonance imaging showed niveau formation in the $\mathrm{CSH}$ and the continuity of the right and left hematomas through the supracerebellar area (Fig. 2). As his laboratory examination revealed prolonged coagulation (prothrombin time international normalization ratio: 3.6), vitamin $\mathrm{K}$ was administered to reverse the coagulation status. As his consciousness deteriorated rapidly, urgent burr hole irrigation for the posterior fossa CSH was performed under local anesthesia in the supine position (Fig. 3a). The CSH in the posterior fossa had the same characteristics as the common supratentorial $\mathrm{CSH}$, which had an outer membrane and hematoma fluid inside. The hematoma was evacuated, then the cavity was washed thoroughly with saline. The supratentorial CSH was evacuated through another burr hole in the usual manner. His consciousness improved within a few hours after the surgery. The postoperative CT scans showed the disappearance of the CSH in the posterior fossa and improvement of the hydrocephalus. Follow-up CT scans taken 3 months after surgery demonstrated no recurrence of the CSH in the posterior fossa (Fig. 3b). The patient provided written informed consent for publication of this report. 


\section{Case Reports in Neurology}

\section{Discussion}

Supratentorial CSH is commonly encountered in neurosurgical practice; it generally appears a few months after mild head injury. It is usually treated with burr hole surgery under local anesthesia. On the other hand, $\mathrm{CSH}$ in the posterior fossa is extremely rare. Only 14 cases have been reported to date [1-13] (Table 1). Of these, 9 patients (64\%) had no history of head injury $[2-4,6,8,10-13]$ and 10 patients $(71 \%)$ had coagulation disorders or anticoagulation/antiplatelet therapy $[1,2,4,6,8-13]$. The CSH in the posterior fossa in our case may not have been caused by the previous head trauma, which was more than 1 year apart from the symptom onset, but could be attributed to the anticoagulation and antiplatelet therapy. Bilateral hematoma is another frequently reported characteristic demonstrated in 8 cases (53\%), including ours $[4,7,8,10-13]$. Despite these clinical characteristics, the developmental mechanism of posterior fossa CSH has not been elucidated yet.

There are some surgical strategies reported for CSH in the posterior fossa. The symptomatic 10 cases underwent surgical procedures, including lateral suboccipital craniotomy, small craniectomy, and burr hole trepanations under general anesthesia. Kurisu et al. [7] and other authors $[10,11]$ reported cases with bilateral posterior fossa $\mathrm{CSH}$, which were operated with two burr holes, one on each side, via a midline suboccipital approach in the supine position. They proposed that burr hole surgery should be performed under general anesthesia because of potentially longer surgical time and prone position required. On the other hand, Takami et al. [12] observed the same level of niveau formation on both sides in axial CT slices, indicating that unilateral one-burr hole surgery may be adequate for this bilateral CSH, which has a connection between the right and left sides. In our case, although the level of the niveau was different between the sides, a single burr hole near the transverse-sigmoid junction allowed to evacuate the hematoma on both sides, suggesting the presence of a connection between each side in the bilateral CSH. We consider that the location of the burr hole near the transverse-sigmoid junction is suitable for accessing the hematoma cavity as the region has a thinner muscle layer, so that the operation can be done with a small skin incision under local anesthesia. Considering that most cases of posterior fossa CSH have coagulation disorders, less invasive burr hole surgery under local anesthesia would be appropriate, even for the bilateral cases.

Hydrocephalus caused by posterior fossa CSH has been described in 6 cases, including ours $[3,6,8,10,12]$. Ventricular drainage was placed in 2 of them $[8,10]$. In the rest of the cases, the hematoma evacuation led to the disappearance of the noncommunicating hydrocephalus. As associated hydrocephalus may deteriorate neurological status rapidly, prompt burr hole surgery under local anesthesia should be taken into account.

In conclusion, a rare case of $\mathrm{CSH}$ in the posterior fossa is reported. One-burr hole surgery under local anesthesia is sufficient to manage this type of CSH, even for bilateral cases. As most cases have coagulation disorders and associated hydrocephalus, less invasive and early treatment is recommended. 
Inoue et al.: Bilateral Chronic Subdural Hematoma in the Posterior Fossa Treated with a Burr Hole Irrigation: A Case Report and Review of the Literature

\section{Statement of Ethics}

The patient provided informed consent to participate in this paper, which was approved by the institutional review board.

\section{Disclosure Statement}

There are no potential conflicts of interest for any of the authors with products or techniques discussed in the paper.

\section{Funding Sources}

There are no financial supports or grants to report. There is no funding information to report.

\section{Author Contributions}

All authors had access to the data and a role in writing the manuscript; there are no disclaimers.

\section{References}

1 Ashkenazi E, Pomeranz S. Nystagmus as the presentation of tentorial incisure subdural haematoma. J Neurol Neurosurg Psychiatry. 1994 Jul;57(7):830-1.

2 Berhouma M, Houissa S, Jemel H, Khaldi M. Spontaneous chronic subdural hematoma of the posterior fossa. J Neuroradiol. 2007 Jul;34(3):213-5.

3 Costa LB Jr, de Andrade A, Valadão GF. Chronic subdural hematoma of the posterior fossa associated with cerebellar hemorrhage: report of rare disease with MRI findings. Arq Neuropsiquiatr. 2004 Mar;62(1):1702.

4 Izumihara A, Orita T, Kajiwara K, Tsurutani T. Simultaneous supra- and infratentorial chronic subdural hematoma. Eur J Radiol. 1993 Apr;16(3):183-5.

5 Kachkov IA, Rusinov AI, Stashuk GA. [Chronic subdural hematoma of the posterior cranial fossa]. Zh Vopr Neirokhir Im N N Burdenko. 1999 Jan-Mar;1(1):30-1.

6 Kanter R, Kanter M, Kirsch W, Rosenberg G. Spontaneous posterior fossa subdural hematoma as a complication of anticoagulation. Neurosurgery. 1984 Aug;15(2):241-2.

7 Kurisu K, Kawabori M, Niiya Y, Ohta Y, Mabuchi S, Houkin K. Bilateral chronic subdural hematomas of the posterior fossae. Neurol Med Chir (Tokyo). 2012;52(11):822-5.

8 Lagares A, Domínguez J, Lobato RD, González P. Bilateral posterior fossa subdural haematomas secondary to anticoagulant therapy. Acta Neurochir (Wien). 1998;140(10):1097-8.

9 Mochizuki Y, Kobayashi T, Kawashima A, Funatsu T, Kawamata T. Chronic subdural hematoma of the posterior fossa treated by suboccipital craniotomy. Surg Neurol Int. 2018 Feb;9:20.

10 Pollo C, Meuli R, Porchet F. Spontaneous bilateral subdural haematomas in the posterior cranial fossa revealed by MRI. Neuroradiology. 2003 Aug;45(8):550-2.

11 Stendel R, Schulte T, Pietilä TA, Suess 0, Brock M. Spontaneous bilateral chronic subdural haematoma of the posterior fossa. Case report and review of the literature. Acta Neurochir (Wien). 2002 May;144(5):497-500. 


\section{Case Reports in Neurology}

\begin{tabular}{|c|c|}
\hline DOI: 10.1159/000498856 & $\begin{array}{l}\text { (c) } 2019 \text { The Author(s). Published by S. Karger AG, Basel } \\
\text { www.karger.com/crn }\end{array}$ \\
\hline
\end{tabular}

Inoue et al:: Bilateral Chronic Subdural Hematoma in the Posterior Fossa Treated with a Burr Hole Irrigation: A Case Report and Review of the Literature

12 Takami H, Oshiro N, Hiraoka F, Murao M, Ide T. Rapid resolution of a spontaneous large chronic subdural haematoma in the posterior fossa under conservative treatment with platelet administration to aplastic anaemia. Clin Neurol Neurosurg. 2013 Oct;115(10):2236-9.

13 Takemoto Y, Matsumoto J, Ohta K, Hasegawa S, Miura M, Kuratsu J. Bilateral posterior fossa chronic subdural hematoma treated with craniectomy: Case report and review of the literature. Surg Neurol Int. 2016 May;7(Suppl 10):S255-8.
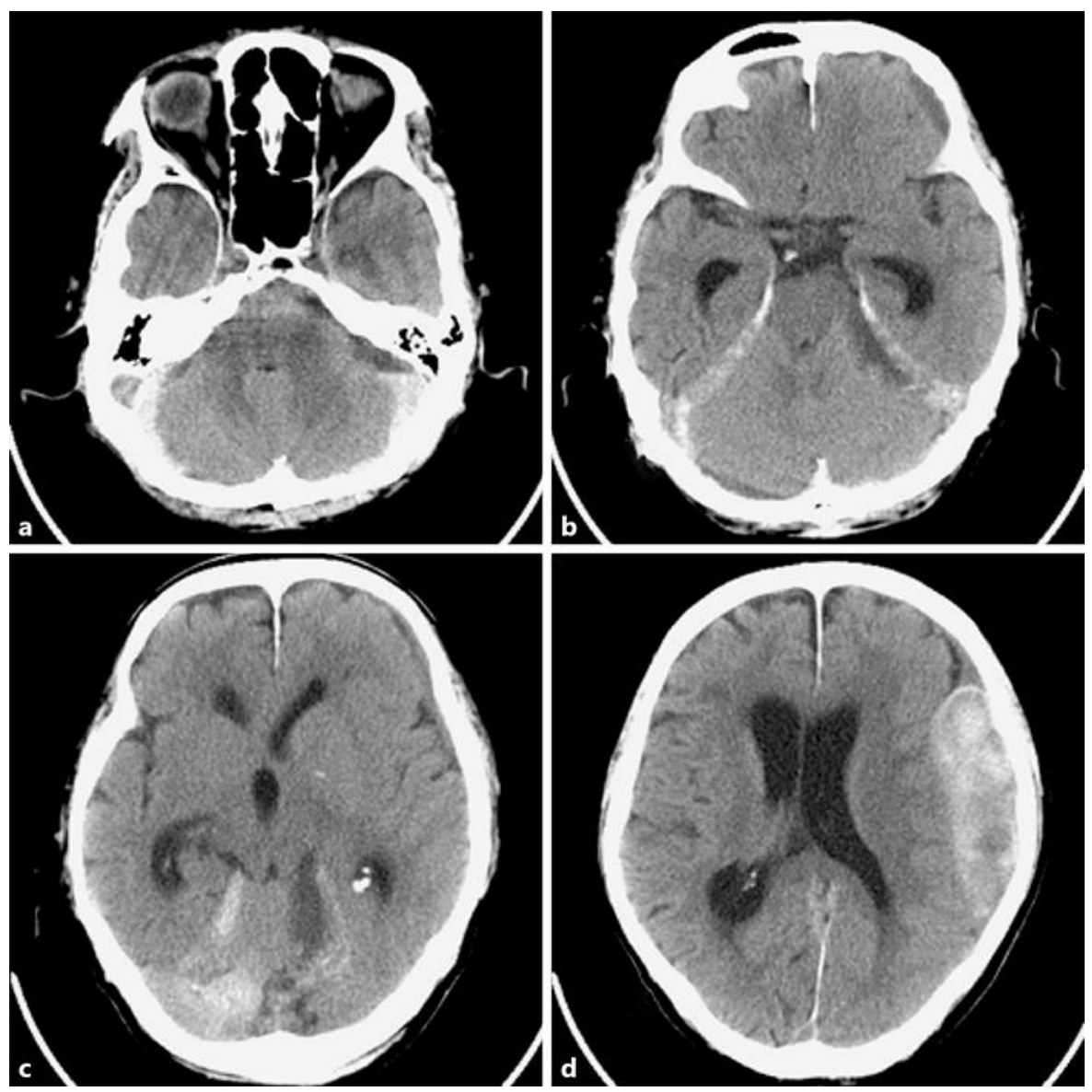

Fig. 1. a-c Preoperative computed tomography scans show bilateral chronic subdural hematoma (CSH) in the posterior fossa associated with moderate hydrocephalus. $\mathbf{d}$ The preexisting CSH in the supratentorial region demonstrated no change. 


\section{Case Reports in Neurology}
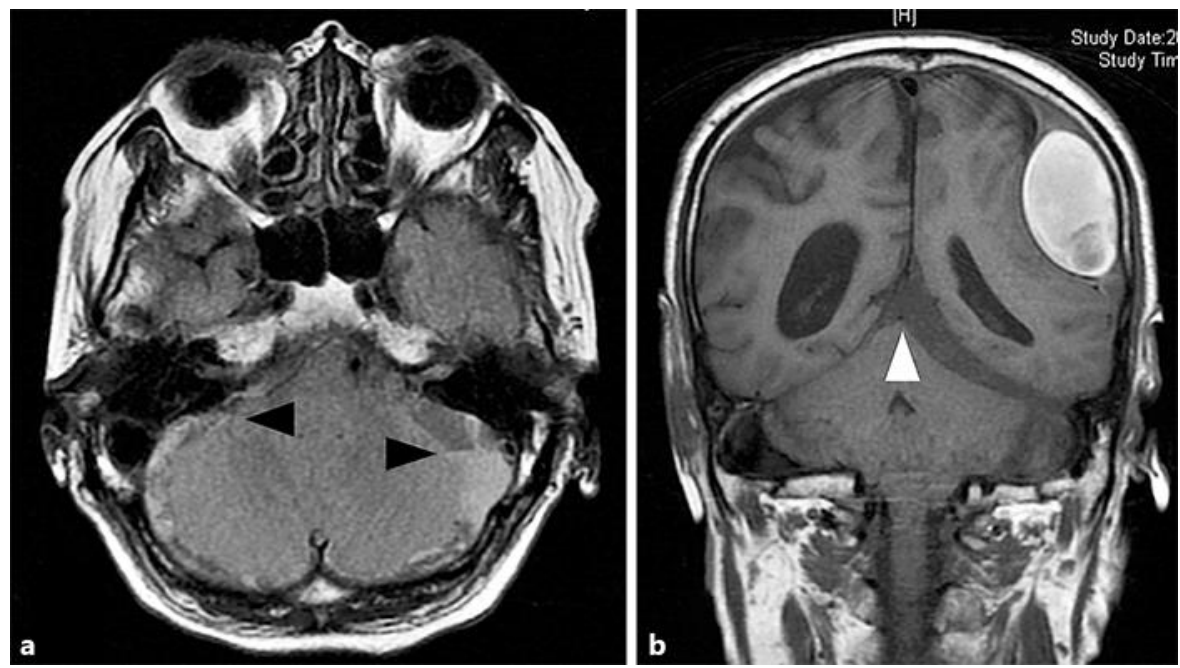

Fig. 2. a A preoperative axial magnetic resonance imaging (MRI) T1-weighted image shows bilateral chronic subdural hematoma (CSH) with niveau formation (black arrowheads). b A coronal MRI scan, flair image, demonstrates the continuity of the posterior fossa CSH through the supracerebellar area (white arrowhead).


Fig. 3. a A 3-dimensional bone window image of the computed tomography (CT) scan shows the location of the burr hole near the transverse-sigmoid junction. $\mathbf{b}$ A postoperative CT scan 3 months after surgery demonstrates disappearance of the chronic subdural hematoma in the posterior fossa. 


\section{Case Reports in Neurology}

\begin{tabular}{l|l}
\hline Case Rep Neurol 2019;11:87-93 \\
\hline DOI: 10.1159/000498856 & $\begin{array}{l}\text { (c) 2019 The Author(s). Published by S. Karger AG, Basel } \\
\text { www.karger.com/crn }\end{array}$ \\
\hline
\end{tabular}

Inoue et al.: Bilateral Chronic Subdural Hematoma in the Posterior Fossa Treated with a Burr Hole Irrigation: A Case Report and Review of the Literature

Table 1. Literature review of chronic subdural hematoma in the posterior fossa

\begin{tabular}{|c|c|c|c|c|c|c|c|c|c|c|}
\hline Ref. & First author & Year & $\begin{array}{l}\text { Age, years/ } \\
\text { sex }\end{array}$ & Side & Trauma & $\begin{array}{l}\text { Coagulation dis- } \\
\text { order }\end{array}$ & Hydrocephalus & Symptoms & Treatment & Outcome \\
\hline 1 & Ashkenazi & 1994 & $65 / \mathrm{F}$ & $\mathrm{L}$ & $\mathrm{N} / \mathrm{A}$ & Yes & No & Vertigo, nystagmus & Craniectomy & GR \\
\hline 2 & Berhouma & 2007 & $38 / \mathrm{F}$ & $\mathrm{R}$ & No & Yes & No & Vertigo, ataxia & Craniectomy & GR \\
\hline 3 & Costa & 2004 & $64 / F$ & $\mathrm{R}$ & No & No & Yes & Somnolence, ataxia & Craniectomy & GR \\
\hline \multirow[t]{2}{*}{4} & Izumihara & 1993 & $72 / \mathrm{F}$ & Bil. & Yes & Yes & No & No & Conservative & GR \\
\hline & & & $70 / \mathrm{M}$ & $\mathrm{L}$ & No & No & No & No & Conservative & GR \\
\hline 5 & Kachkov & 1999 & $41 / \mathrm{F}$ & $\mathrm{R}$ & $\mathrm{N} / \mathrm{A}$ & $\mathrm{N} / \mathrm{A}$ & No & Ataxia & Surgical evacuation & GR \\
\hline 6 & Kanter & 1984 & $59 / F$ & $\mathrm{~L}$ & No & Yes & Yes & Coma & Surgical evacuation & MR \\
\hline 7 & Kurisu & 2012 & $86 / \mathrm{F}$ & Bil. & Yes & No & No & Stupor, tetraparesis & Trepanations & GR \\
\hline 8 & Lagares & 1998 & $65 / F$ & Bil. & No & Yes & Yes, EVD & No & Conservative & GR \\
\hline 9 & Mochizuki & 2018 & $71 / \mathrm{F}$ & $\mathrm{L}$ & Surgery & Yes & No & Somnolence, ataxia & Craniectomy & GR \\
\hline 10 & Pollo & 2003 & $52 / \mathrm{F}$ & Bil. & No & Yes & Yes, EVD & Tetraparesis, coma & Trepanations & GR \\
\hline 11 & Stendel & 2002 & $70 / \mathrm{F}$ & Bil. & No & Yes & No & Vertigo, ataxia & Trepanations & GR \\
\hline 12 & Takami & 2013 & $83 / F$ & Bil. & No & Yes & Yes & Headache, ataxia & Conservative & GR \\
\hline \multirow[t]{2}{*}{13} & Takemoto & 2016 & $69 / F$ & Bil. & No & Yes & No & Somnolence, ataxia & Craniectomy & MR \\
\hline & Our case & 2018 & $74 / \mathrm{M}$ & Bil. & Yes & Yes & Yes & Somnolence & Trepanation & GR \\
\hline
\end{tabular}

L, left; R, right; Bil., bilateral; GR, good recovery; MR, moderate recovery; EVD, external ventricular drainage; N/A, not available. 